\title{
Universiteit
}

Leiden

The Netherlands

\section{Iron and steel in Chinese residential buildings: a dynamic analysis}

\author{
Hu, M.; Pauliak, S.; Wang, T.; Huppes, G.; Voet, E. van der; Müller, D.B.
}

\section{Citation}

Hu, M., Pauliak, S., Wang, T., Huppes, G., Voet, E. van der, \& Müller, D. B. (2010). Iron and steel in Chinese residential buildings: a dynamic analysis. Resources Conservation And Recycling, 54(9), 591-600. doi:10.1016/j.resconrec.2009.10.016

Version: Publisher's Version

License: $\quad$ Licensed under Article 25fa Copyright Act/Law (Amendment Taverne)

Downloaded from: https://hdl.handle.net/1887/3193754

Note: To cite this publication please use the final published version (if applicable). 


\title{
Iron and steel in Chinese residential buildings: A dynamic analysis
}

\author{
Mingming $\mathrm{Hu}^{\mathrm{a}, \mathrm{b}, *}$, Stefan Pauliuk ${ }^{\mathrm{c}}$, Tao Wang ${ }^{\mathrm{c}}$, Gjalt Huppes ${ }^{\mathrm{b}}$, Ester van $\operatorname{der}_{\text {Voet }}{ }^{\mathrm{b}}$, Daniel B. Müller ${ }^{\mathrm{c}}$ \\ a Faculty of Construction Management and Real Estate, Chongqing University, Chongqing 400015, PR China \\ ${ }^{\mathrm{b}}$ CML - Institute of Environmental Sciences, Leiden University, Einsteinweg 2, 2333 CC Leiden, The Netherlands \\ ${ }^{\mathrm{c}}$ Department of Hydraulic and Environmental Engineering, Norwegian University of Science and Technology, S P Andersens vei 5, 7491 Trondheim, Norway
}

\section{A R T I C L E I N F O}

\section{Article history:}

Received 1 August 2009

Received in revised form 5 October 2009

Accepted 6 October 2009

\section{Keywords:}

Industrial ecology

Dynamic material flow analysis

Iron and steel

Housing

China

\begin{abstract}
A B S T R A C T
The rise of China to become world largest iron and steel producer and consumer since the late 1990s can be largely attributed to urbanization, with about $20 \%$ of China's steel output used by residential buildings, and about 50\% for the construction sector as a whole. Previously, a dynamic material flow analysis (MFA) model was developed to analyze the dynamics of the rural and the urban housing systems in China. This model is expanded here to specifically analyze iron and steel demand and scrap availability from the housing sector. The evolution of China's housing stock and related steel is simulated from 1900 through 2100. For almost all scenarios, the simulation results indicate a strong drop in steel demand for new housing construction over the next decades, due to the expected lengthening of the - presently extremely short - life span of residential buildings. From an environmental as well as a resource conservation point of view, this is a reassuring conclusion. Calculations for the farther future indicate that the demand for steel will not just decrease but will rather oscillate: the longer the life spans of buildings, the stronger the oscillation. The downside of this development would be the overcapacities in steel production. A scenario with slightly lower life spans but a strong emphasis on secondary steel production might reduce the oscillation at moderate environmental costs.
\end{abstract}

(c) 2009 Elsevier B.V. All rights reserved.

\section{Introduction}

The sharp increase in material demand in China has grown the country the largest iron and steel consumer as well as the largest producer in the world. China's annual use of iron per capita has risen from $90 \mathrm{~kg} /$ year in 2000 to $370 \mathrm{~kg} /$ year in 2008, while the world's per capita iron use increased in the same period from $130 \mathrm{~kg} /$ year to $190 \mathrm{~kg} /$ year (CISA, 2008; WSA, 2008, 2009). Along with that, production volume in China has more than tripled, from 129 to $500 \mathrm{Mt}$ (million metric tons) between 2000 and 2008, which now accounts for $38 \%$ of world crude steel production (Price et al., 2002; WSA, 2009). China has very limited domestic scrap supply (Lu, 2002) and limited quantity and quality of iron ore. For this reason, China's steel production mainly relies on virgin minerals, which are largely imported (Wang et al., 2007, 2008). How China's demand will develop in the future will inevitable exert an influence on the global raw material market. Moreover, the extraction and production of iron and steel impose considerable energy and environmental consequences, which is especially true for the iron ore

\footnotetext{
* Corresponding author at: Room 6.27, Faculty of Civil Engineering and Geosciences, Section Materials \& Environment, Stevinweg 1, 2628 CN Delft, The Netherlands. Tel.: +31015278 85 69; fax: +31015278 8162 .

E-mail addresses: Hu@cml.leidenuniv.nl, mming.hu@gmail.com (M. Hu).
}

based ${ }^{1}$ production in China. Therefore, it is important to understand the development mechanism of steel demand and scrap supply in China, and its economic and environmental implications.

The recent rise of steel demand in China can be largely attributed to the unprecedented urbanization in the country. In 2004, apparent steel consumption in China was $286 \mathrm{Mt} / \mathrm{year}$, half of which is used in the construction industry while residential buildings account for 19\% (Fig. 1). A short-term forecast for China's future steel demand has been made by the Development Research Center of the State Council of China (DRCSCC), which indicates that steel demand in China will further increase by 50\% from 2005 to 2010 (DRCSCC, 2005).

An effort for long-term projection has been done by Yang and Kohler (2008) for the mass input and output of China's building and infrastructure systems. This research analyses the historical evolution of the Chinese building and infrastructure stock from 1978 to 2005 and estimates the future mass input and output through 2050. It provides valuable information about China's building stock. However, this model neglects the ageing of the building stock and 


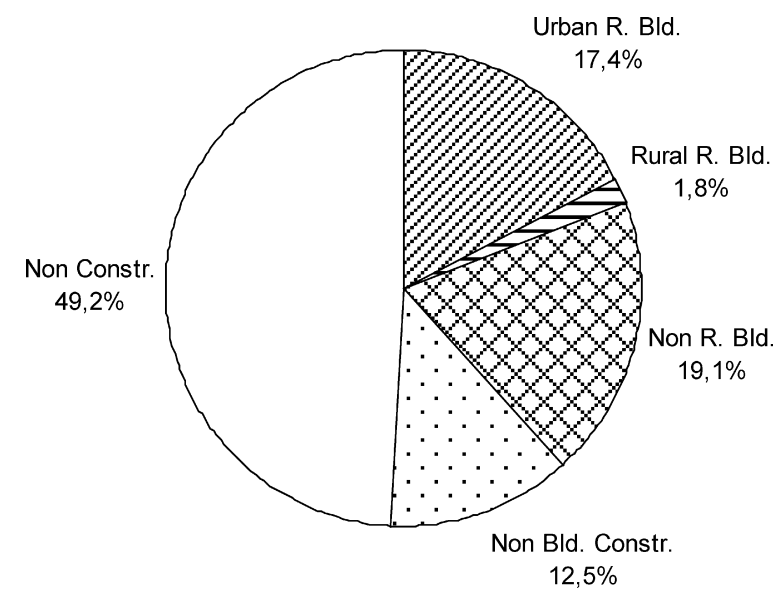

Fig. 1. Apparent steel consumption in China 2004. Non Constr. = Non-construction; Non Bld. Constr. = Non-building construction; Non R. Bld. = Non-residential building; Rural R. Bld. = Rural residential building; Urban R. Bld. = Urban residential building. Source: DRCSCC (2005).

assumes that the demolition rate is proportional to the total stock, and is therefore limited in its capacity to forecast long-term changes in construction and demolition activities and their related material flows.

A generic dynamic MFA model for simultaneously determining the resource demand and waste generation through estimations of the population, its lifestyle, technology, and product lifetime has been proposed by Müller $(2004,2006)$. This model uses stock dynamics approach that tracks all vintage classes (year by year) individually and computes the demolition activities based on the estimates of probability distribution functions for the lifetimes of all vintage classes, and therefore provides a better framework to analyze the material diffusion in long lifespan goods, such as residential buildings. Based on the approach, Hu et al. (2009) developed a dynamic MFA model to simulate the evolution of the floor area stocks in China's urban and rural housing systems from 1900 through 2100 . This model is expanded in this study to specifically cover China's iron and steel demand for residential construction and the scrap availability from housing demolition.

Through the dynamic MFA for steel in China's housing stock, this study aims to answer the following questions: (1) how the housing related steel demand in China will likely develop in the future; (2) what the implications of such development are for the steel industry and how the potentially negative impacts on the industry could be mitigated; and (3) what the environmental consequences are for various options for mitigating the impacts.

\section{Methods}

\subsection{System definition}

The model presented in Fig. 2 represents a material flow analysis (MFA) for the floor area and selected construction material (steel) in China's residential building stock. The system is divided into two sub-systems reflecting the rural and urban housing stocks. The two sub-systems are linked through migration flows from rural to urban areas $\left(m_{\mathrm{u}}\right)$ and vice versa $\left(m_{\mathrm{r}}\right)$. Each sub-system involves three types of processes, illustrated with rectangles: population within the region $(P)$, housing floor area of the region $(A)$ and related material $(M)$. All the processes have a state variable $\left(P_{\mathrm{r}}, A_{\mathrm{r}}, M_{\mathrm{r}}\right.$ for rural area or $P_{\mathrm{u}}, A_{\mathrm{u}}, M_{\mathrm{u}}$ for urban area) and a derivative, which is the net stock accumulation $\left(\mathrm{d} P_{\mathrm{r}} / \mathrm{d} t, \mathrm{~d} A_{\mathrm{r}} / \mathrm{d} t, \mathrm{~d} M_{\mathrm{r}} / \mathrm{d} t\right.$ or $\mathrm{d} P_{\mathrm{u}} / \mathrm{d} t, \mathrm{~d} A_{\mathrm{u}} / \mathrm{d} t$, $\mathrm{d} M_{\mathrm{u}} / \mathrm{d} t$ ). Each population process has three pairs of input and output flows which are denoted, respectively, as: $b$ and $d$ for annual inflow and outflow of population led by birth and death, $i$ and $e$ for annual immigration and emigration crossing China's border, and $m_{\mathrm{u}}$ and $m_{\mathrm{r}}$ for internal migration flows from rural to urban and vice versa. The integrated effect of these flows on the share of people living in rural and urban can be indicated by the urbanization rate. In this study, the urbanization rate $(u)$ and the total national population $(P)$ are used as determinants for China's rural $\left(P_{\mathrm{r}}\right)$ and urban $\left(P_{\mathrm{u}}\right)$ population. Each housing floor area process has an input $\left(\mathrm{d} A_{\mathrm{r}, \text { in }}\right.$ or $\left.\mathrm{d} A_{\mathrm{u}, \text { in }}\right)$ and an output flow $\left(\mathrm{d} A_{\mathrm{r}, \text { out }}\right.$ or $\left.\mathrm{d} A_{\mathrm{u}, \text { out }}\right)$, represented with straight-line arrows and ovals. Housing floor area stock is shaped by population $\left(P_{\mathrm{r}}\right.$ or $P_{\mathrm{u}}$ and per capita floor area $\left(A_{\mathrm{rc}}\right.$ or $\left.A_{\mathrm{uc}}\right)$; output flow is the delay of past input, determined by building lifetime function $\left(L_{\mathrm{r}} \sim N\left(\tau_{\mathrm{r}}, \sigma_{\mathrm{r}}\right)\right.$ or $\left.L_{\mathrm{u}} \sim N\left(\tau_{\mathrm{u}}, \sigma_{\mathrm{u}}\right)\right)$; and the future input flow is formed to maintain the demanded size of in-use housing floor area stock. Input flow of material $\left(\mathrm{d} M_{\mathrm{r}, \text { in }}\right.$ or $\left.\mathrm{d} M_{\mathrm{u}, \text { in }}\right)$ is coupled with floor area through the material intensity $\left(M_{\mathrm{ra}}\right.$ or $\left.M_{\mathrm{ua}}\right)$, and the output flow of material $\left(\mathrm{d} M_{\mathrm{r}, \text { out }}\right.$ or $\left.\mathrm{d} M_{\mathrm{u}, \text { out }}\right)$ is determined by delaying the input. The underlying equations are given in Appendix A and the eight external parameters for the model are listed as follows:

$\begin{array}{ll}P & \text { National total population } \\ u & \text { Urbanization rate }=P_{\mathrm{u}} / P \\ A_{\mathrm{rc}} & \text { Per capita floor area in rural region } \\ A_{\mathrm{uc}} & \text { Per capita floor area in urban system } \\ L_{\mathrm{r}} & \text { Lifetime distribution of rural housing }\left(L_{\mathrm{r}} \sim N\left(\tau_{\mathrm{r}}, \sigma_{\mathrm{r}}\right)\right) \\ L_{\mathrm{u}} & \text { Lifetime distribution of urban housing }\left(L_{\mathrm{u}} \sim N\left(\tau_{\mathrm{u}}, \sigma_{\mathrm{u}}\right)\right) \\ M_{\mathrm{ra}} & \text { Material intensity per unit floor area in rural region } \\ M_{\mathrm{ua}} & \text { Material intensity per unit floor area in urban system }\end{array}$

\subsection{Model parameter quantification}

\subsubsection{Steel intensity}

Very few data are available for the steel intensity in different dwelling vintages. Little iron and steel was used in Chinese housing construction before 1950s when concrete structure became popular in urban residential construction. Typical Chinese dwellings at the beginning of 20th century were one or two-floor buildings built from local materials such as clay, bricks, wood, bamboo et al. A recent survey estimates the average steel intensity in China's urban residential construction in 2004 to be $36.5 \mathrm{~kg} / \mathrm{m}^{2}$ (DRCSCC, 2005). Due to the promotion of steel structures, the same study expects the steel intensity in urban residential construction to further increase to $41.3 \mathrm{~kg} / \mathrm{m}^{2}$ by 2010 (DRCSCC, 2005; illustrated as dots in Fig. 3b), however, the trend for the longer term is less clear. From one side, the steel intensity may continue to rise if China's high steel production capacity will lead to low cost construction steel, or if the increase of high residential buildings will employ more high steel content structures in residential construction. From another side, technical innovation may minimize the steel use in concrete structure, which is dominant in China's urban residential buildings. For instance, the steel content in concrete may be substituted by glass fiber, if the technical development will drop the cost of glass fiber to be competitive, or when developments in the steel market will cause the steel prices to rise significantly. We therefore assume that the steel intensity in China's residential construction follows a (double) logistic curve with initial level zero, with the measured level of 2004, and with different assumed saturation levels. Three potential future paths are investigated, representing trends of increasing, decreasing, and stabilizing steel intensity (Fig. 3b).

The variance for steel intensity in urban housing construction is based on a survey for 100 residential buildings in Beijing (Liu and $\mathrm{Hu}, 2006)$. The survey shows the shearing-force structure dwellings have the highest steel intensity as $97.1 \mathrm{~kg} / \mathrm{m}^{2}$, while the brickconcrete structure dwellings have the lowest value as $23.4 \mathrm{~kg} / \mathrm{m}^{2}$. We assume that by 2100 , for increasing path, due to the increase of high dwellings and the promotion of steel intensive structure in residential construction, the average steel intensity in China's urban 


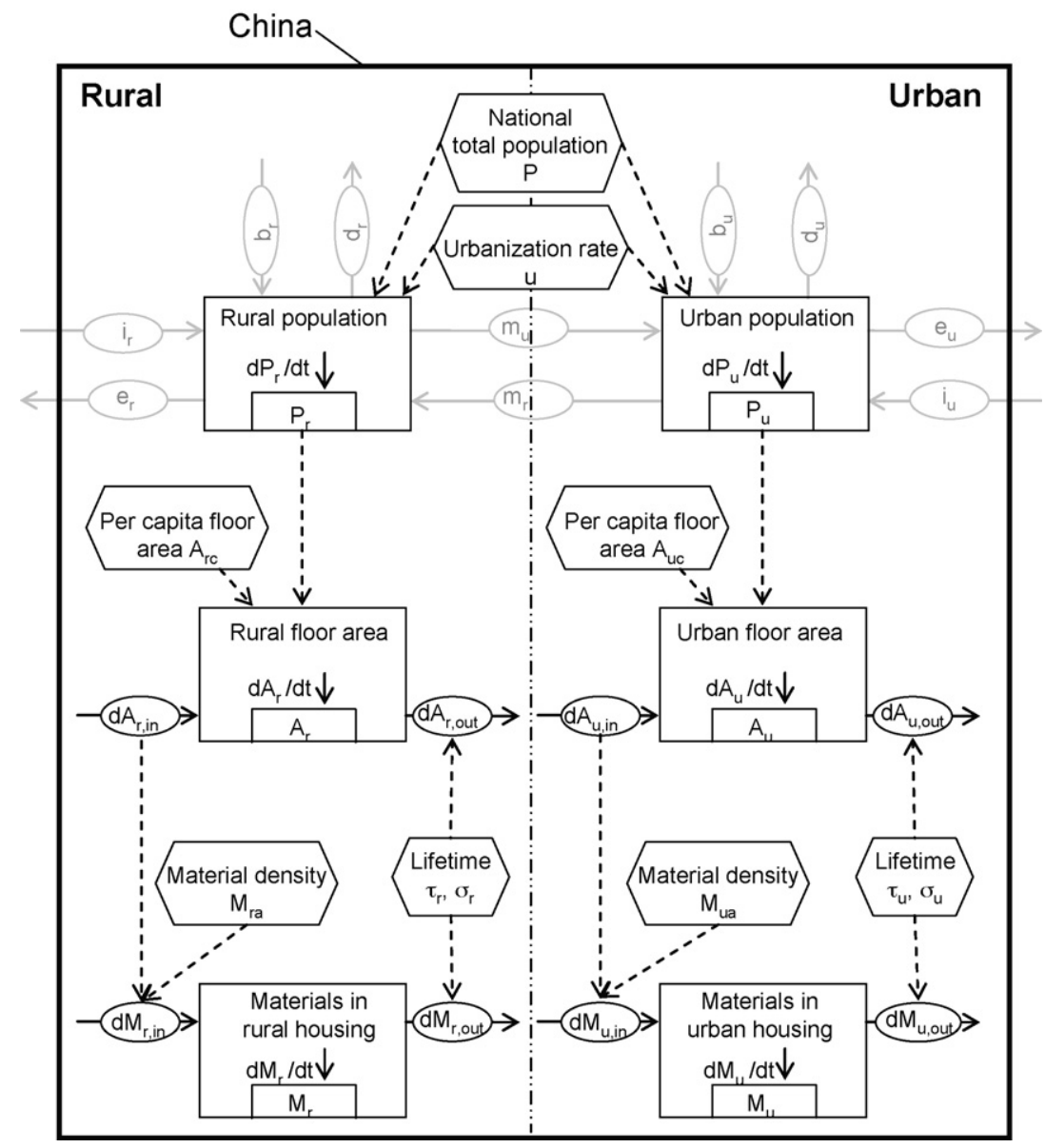

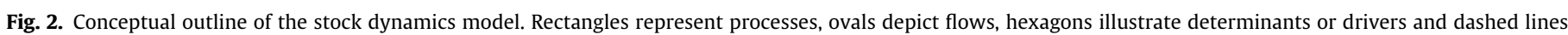
represent influences between variables.

residential construction will approach the observed high value $97.1 \mathrm{~kg} / \mathrm{m}^{2}$ of shearing-force structure; while for decreasing path, due to technical innovation, for instance, high density concrete or glass fiber, the average steel intensity in China's urban residential construction will decline to the observed low value $23.4 \mathrm{~kg} / \mathrm{m}^{2}$ of brick-concrete structure. The medium path is assumed as that, after a continuous rise till around 2050, the steel intensity in China's urban residential will stay at near $60 \mathrm{~kg} / \mathrm{m}^{2}$, the middle point of the variance range, through 2100.

Very little steel has been used in China's rural housing. In China, rural residential construction is in a period of transition from brickconcrete to reinforce concrete structure. Since brick and other low steel buildings still account for a big share of the annual completed rural houses, instead of per unit floor area steel use, per rural capita purchased steel is used to estimate the steel demand in rural residential construction (DRCSCC, 2005). Historical figures of per capita purchased steel can be found in DRCSCC report for 1999-2003. Assuming all the rural purchased steel was used in residential construction, the steel intensities for rural housing during 1999-2003 are obtained by dividing the rural purchased steel with the completed rural housing floor area at corresponding year, as around $5.0-5.5 \mathrm{~kg} / \mathrm{m}^{2}$ (dots in Fig. 3a). This assumption may lead to over-estimation, because a part of rural purchased steel might have ended up in public buildings or infrastructures. However, even with (a) Steel intensity in rural housing (Mra)

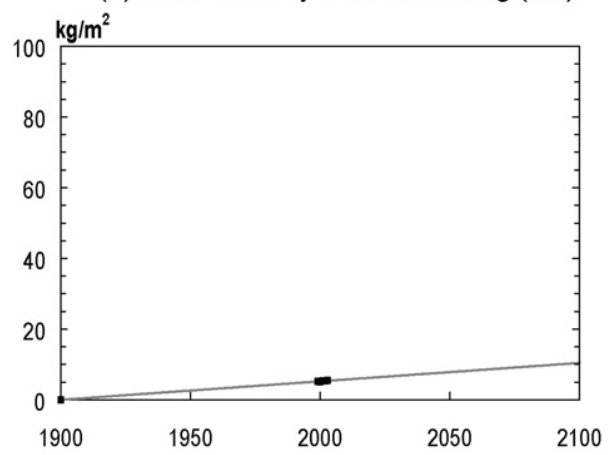

(b) Steel intensity in urban housing (Mua)

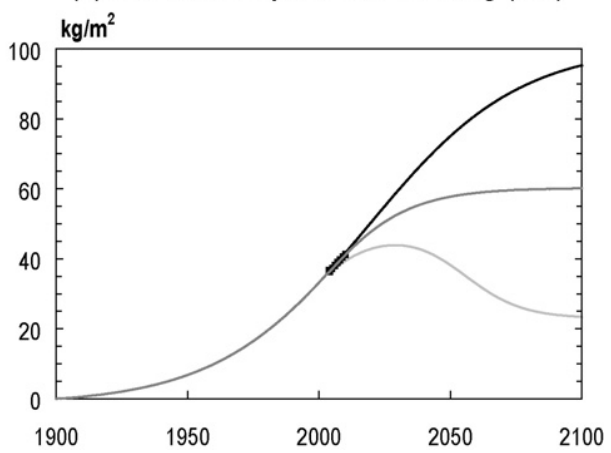

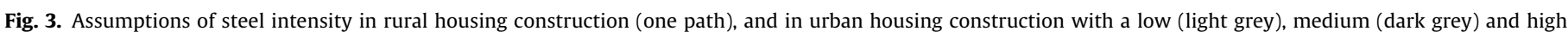
(black) variant from 2005 until 2100. Dots are figures quoted from DRCSCC (2005). 
Urban
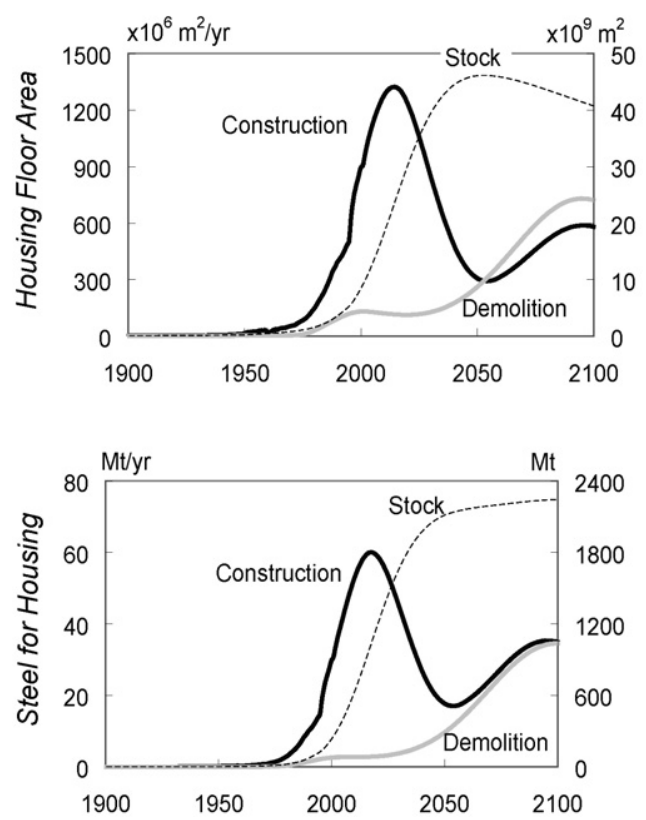

Rural
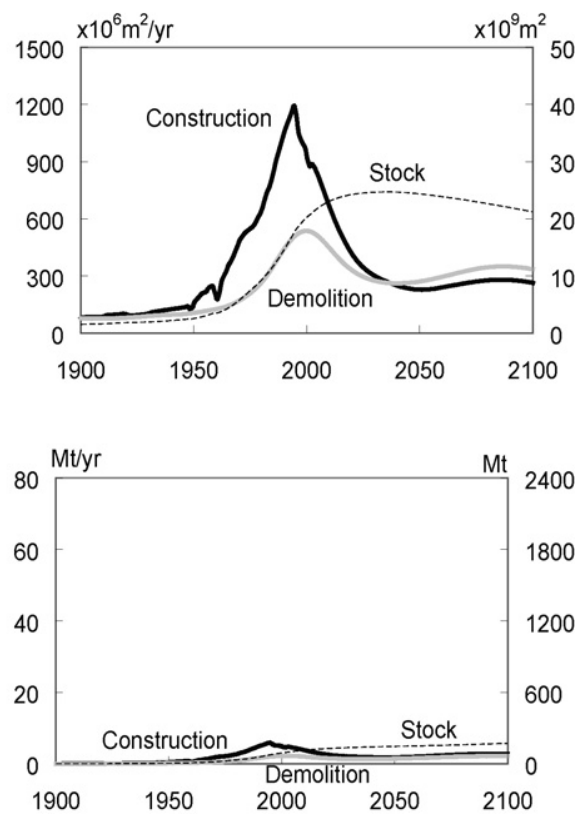

Fig. 4. Simulation results for the medium variant. Stocks are measured on the right axis and flows on the left.

the high estimation, the steel intensity in rural residential construction consumption is still less than $15 \%$ of that in urban. Therefore, for the purpose of anticipating the residential steel demand in the future, we focus mainly on the urban housing stock in China. Only one growth path is estimated for steel intensity in future rural housing, due to its relatively insignificant role. Steel intensity in rural residential construction is estimated to have increased linearly from 0 in 1900 to $5.0 \mathrm{~kg} / \mathrm{m}^{2}$ in 2000 and will continue the growth rate to reach $10.4 \mathrm{~kg} / \mathrm{m}^{2}$ in 2100 .

\subsubsection{Other parameters}

For the other six external parameters: population $(P)$, urbanization rate $(u)$, per capital floor area in rural $\left(A_{\mathrm{rc}}\right)$ and urban $\left(A_{\mathrm{uc}}\right)$, lifetime distribution of rural housing $\left(L_{\mathrm{r}}\right)$ and urban housing $\left(L_{\mathrm{u}}\right)$, the same calibration as adopted in the early floor area stock dynamics model (Hu et al., 2009) is used here and presented in Fig. B1 (Appendix B). Historical figures of the parameters are from 1900 until 2006. Data on total national population, urbanization rate, and per capita floor area in rural and urban regions are collected from China Statistic Yearbooks (NBSC, 2005, 2007). Different projections, representing low, medium and high variants are estimated for the period from 2007 until 2100. The variations in these assumptions allow us to cover a wide range of possible development paths and to compare the influence of changes in one or a group of parameters on the entire system (see Section 3.2).

Future population is quoted from the United Nations Population Division (UNPD, 2003, 2006, 2007) with shrinking, saturating and continuous growing paths for the low, medium and high variants, respectively. Future urbanization rate is assumed to saturate at a level of $70 \%$ for the medium variant, and $56 \%$ and $84 \%$ for low and high variants, respectively. Future per capita floor area in rural housing is assumed to saturate at a level of 60 square meters per capita for the medium variant, and 48 and 72 for low and high variants, respectively. The corresponding figures for urban housing is 50 square meters per capita for the medium variant, and 40 and 60 for low and high variants, respectively.

The lifetime parameter is the most important but least understood factor. It is assumed to follow a normal distribution as in Müller (2006), Bergsdal et al. (2007) and so on. The mean values of the lifetime functions are represented by the estimated average lifetime of dwellings, and the corresponding standard deviations are assumed to be $30 \%$ of the means. The average lifetime of rural

Table 1

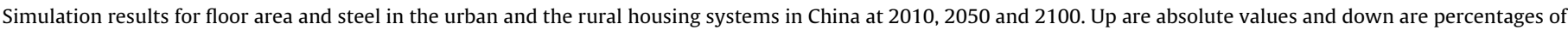
total national volumes.

\begin{tabular}{|c|c|c|c|c|c|c|c|}
\hline \multirow[t]{2}{*}{ Stocks/flows } & & \multicolumn{3}{|l|}{ Urban } & \multicolumn{3}{|l|}{ Rural } \\
\hline & & 2010 & 2050 & 2100 & 2010 & 2050 & 2100 \\
\hline \multirow{6}{*}{ Floor area } & $A\left(\mathrm{~m}^{2}\right)$ & $1.81 \mathrm{e} 10$ & $4.61 \mathrm{e} 10$ & $4.07 \mathrm{e} 10$ & $2.25 \mathrm{e} 10$ & $2.41 \mathrm{e} 10$ & $2.10 \mathrm{e} 10$ \\
\hline & $(\%)$ & $45 \%$ & $66 \%$ & $66 \%$ & $55 \%$ & $34 \%$ & $34 \%$ \\
\hline & $\mathrm{d} A_{\text {in }} / \mathrm{d} t\left(\mathrm{~m}^{2} /\right.$ year $)$ & $12.8 \mathrm{e} 08$ & $3.08 \mathrm{e} 08$ & $5.81 \mathrm{e} 08$ & $6.54 \mathrm{e} 08$ & $2.28 \mathrm{e} 08$ & $2.64 \mathrm{e} 08$ \\
\hline & $(\%)$ & $66 \%$ & $57 \%$ & $69 \%$ & $34 \%$ & $43 \%$ & $31 \%$ \\
\hline & $\mathrm{d} A_{\text {out }} / \mathrm{d} t\left(\mathrm{~m}^{2} /\right.$ year $)$ & $1.21 \mathrm{e} 08$ & $2.61 \mathrm{e} 08$ & $7.22 \mathrm{e} 08$ & $4.42 \mathrm{e} 08$ & $2.72 \mathrm{e} 08$ & $3.35 \mathrm{e} 08$ \\
\hline & $(\%)$ & $21 \%$ & $49 \%$ & $68 \%$ & $79 \%$ & $51 \%$ & $32 \%$ \\
\hline \multirow{6}{*}{ Steel } & $M(\mathrm{Mt})$ & 614 & 2110 & 2240 & 114 & 147 & 172 \\
\hline & $(\%)$ & $84 \%$ & $94 \%$ & $93 \%$ & $16 \%$ & $6 \%$ & $7 \%$ \\
\hline & $\mathrm{d} M_{\mathrm{in}} / \mathrm{d} t(\mathrm{Mt} /$ year $)$ & 52.4 & 17.8 & 34.9 & 3.77 & 1.79 & 2.75 \\
\hline & $(\%)$ & $93 \%$ & $91 \%$ & $93 \%$ & $7 \%$ & $9 \%$ & $7 \%$ \\
\hline & $\mathrm{d} M_{\text {out }} / \mathrm{d} t(\mathrm{Mt} /$ year) & 2.72 & 9.56 & 34.5 & 1.99 & 1.43 & 2.16 \\
\hline & $(\%)$ & $58 \%$ & $87 \%$ & $94 \%$ & $42 \%$ & $13 \%$ & $6 \%$ \\
\hline
\end{tabular}


houses is assumed to be 20 years before 1978 , and to increase gradually to 30,75 and 100 years since then for the low, medium and high variants, respectively, considering the significant improvement in rural residential condition since China's economic reform in 1978. For urban housing, considering a generation of low quality, functionally defect houses constructed during China's Cultural Revolution, which were mostly replaced by the end of the 20th century (BMCCC, 1999), the medium scenario assumes the average dwelling lifetime to be 50 years before 1966 , and then drop to 15 years during 1966-1971 and then gradually increase to 75 years. The low and high variants in 2100 are assumed to be 30 and 100 years, respectively. More background information regarding the collection of historical figures and projections for the parameters of lifetime, per capita floor area, urbanization rate and population can be found in Hu et al. (2009).

\section{Results and discussion}

\subsection{Simulation results}

Simulations are performed on the basis of the parameter variations discussed in the previous section. The base case scenario, for which the results are presented in this section, is constructed by applying the medium values for all input parameters. Fig. 4 shows the results. The base case scenario results for floor area and steel in China's urban and rural housing systems at 2010, 2050 and 2100 , representing the near, the medium distant and the far distant future, are listed in Table 1 with both absolute value and the percentage in the total national volume.

The results show that, in a distant future, the housing related steel demand and scrap supply will be clearly concentrated in urban system, though the levels of construction and demotion actives will be still comparable for both the rural and the urban housing systems. In 2050 , more than $91 \%$ of residential steel demand and $87 \%$ of scrap from housing demolition are expected from urban dwellings, and the urban proportions will rise further through 2100. Both the steel demand and scrap supply from rural housing has right peaked in the past few years. The steel in rural in-use housing stock and the related input and output steel flows are expected to stay at the current low levels through 2100.

A strong oscillation in urban residential steel demand is indicated by the base case scenario. The results show that urban residential construction will reach a peak of 1.3 billion square meters per year around 2011, subsequently, declines for about 40-50 years to about a quarter of the peak of new construction. Coupled with that, the steel demand for urban residential construction is going to drop by a factor of 3.5, from $60 \mathrm{Mt} /$ year in around 2017 to $17 \mathrm{Mt} /$ year in around 2054 . The oscillation is a consequence of

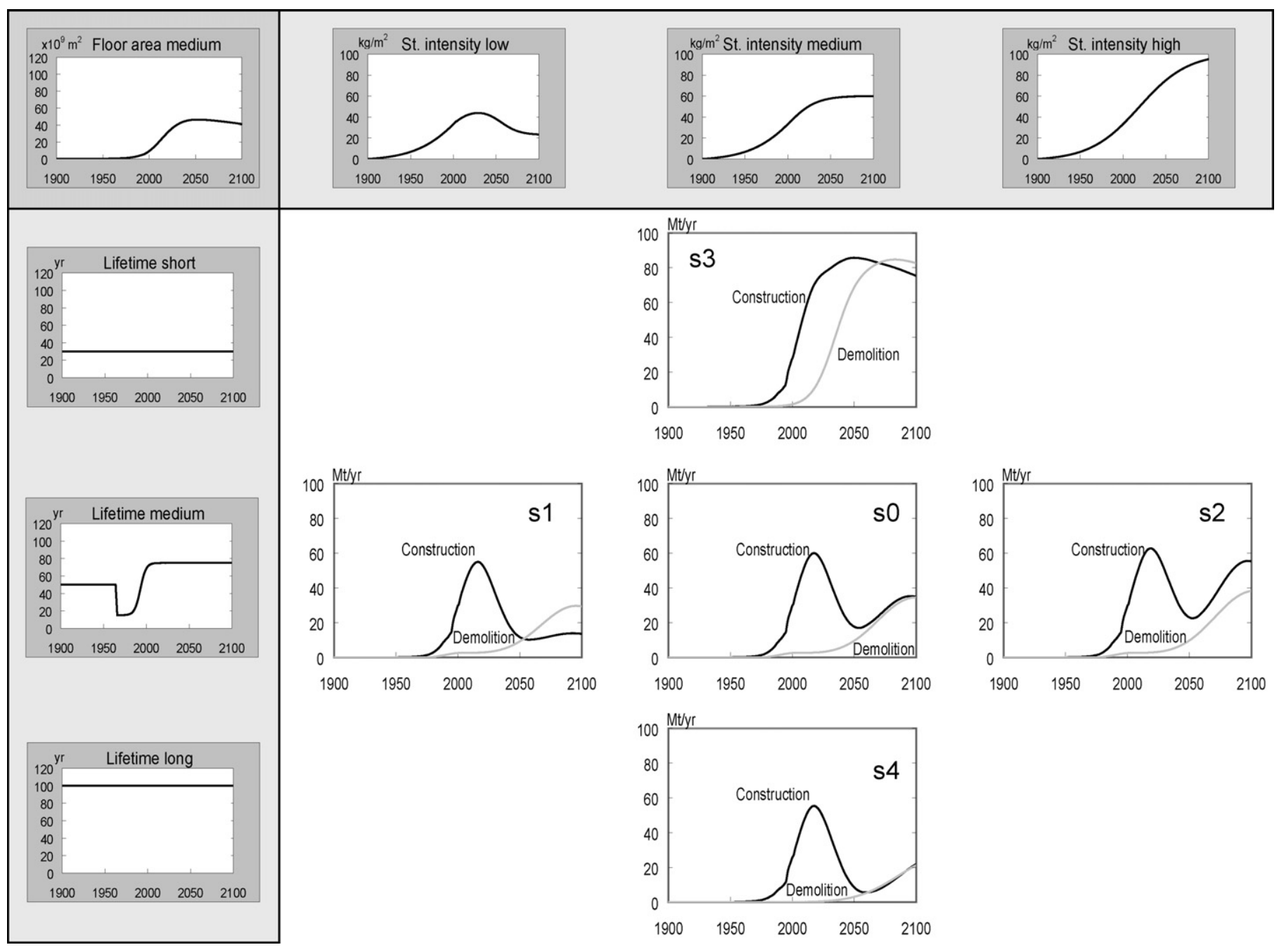

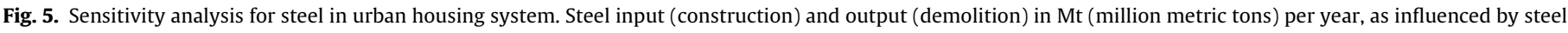

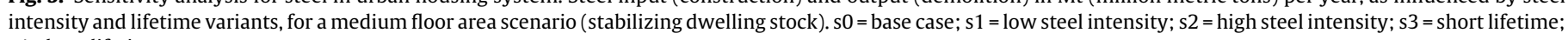
s4 = long lifetime. 
the fast growth in the past: the build-up time of the housing stock (ca. 30 years), is shorter than the expected lifetime of the buildings. The first rise of new construction is caused by the growth in stock demand, and when the saturation of the stock occurs, the demand for new construction will be due to replacement only. Because of the long dwelling lifetime, the demand for replacement will kick-in only after 2050 , and a period of low demand for new construction emerges, so the oscillation in residential steel demand occurs.

This period of low replacement also indicates that the volume of scrap from urban residential demolition will stay at current low level for a couple of decades. It means that, right now, steel stock in residential buildings is being built up which requires primary ore resources. Only approaching the second half of the 21 st century, due to the oscillation in new construction and the kick-in of the replacement for dwellings erected during the first surge of construction, obsolete scrap will be possible to be a major resource for residential steel demand.

\subsection{Sensitivity analysis}

The simulation results presented in the previous section are based on the medium variant for all parameter functions. As there are significant uncertainties regarding how these determinants will behave in the future, in this section, the effect of each determinant (floor area stock, steel intensity and dwelling lifetime) is tested indi- vidually for its low, medium, and high variants. The widespread of parameter assumptions is chosen to capture a large range of possible scenarios, as shown in Figs. 5 and 6.

The results are illustrated only for steel input (construction) and scrap output (demolition) of urban residential buildings. Fig. 5 shows the influences of the average dwelling lifetime (in column) and the steel intensity in residential construction (in row) for the medium housing floor area scenario (left-up corner; stabilizing dwelling stock). Fig. 6 shows the impacts of housing floor area scenario (in column; shrinking, stabilizing and increasing dwelling stocks), when dwelling lifetime and steel intensity are both at their medium variants.

The sensitivity analysis for steel in urban housing construction shows that an oscillation in new construction can be expected to occur. The oscillation seems to be there independent of variations in the floor area and steel intensity within the projection period. The life span of the buildings however does make a difference: in the low lifetime scenario, when the lifetime is assumed to be 30 years, the oscillation is not visible. Floor area and steel intensity do have some influence on the magnitude of the oscillation: the larger the future housing floor area stock and the steel intensity are, the less dramatic the oscillations will be.

Obsolete scrap generation from urban housing demolition is increasing in all scenarios. If the floor area saturates and the steel intensity in buildings remains on current levels, the volume of

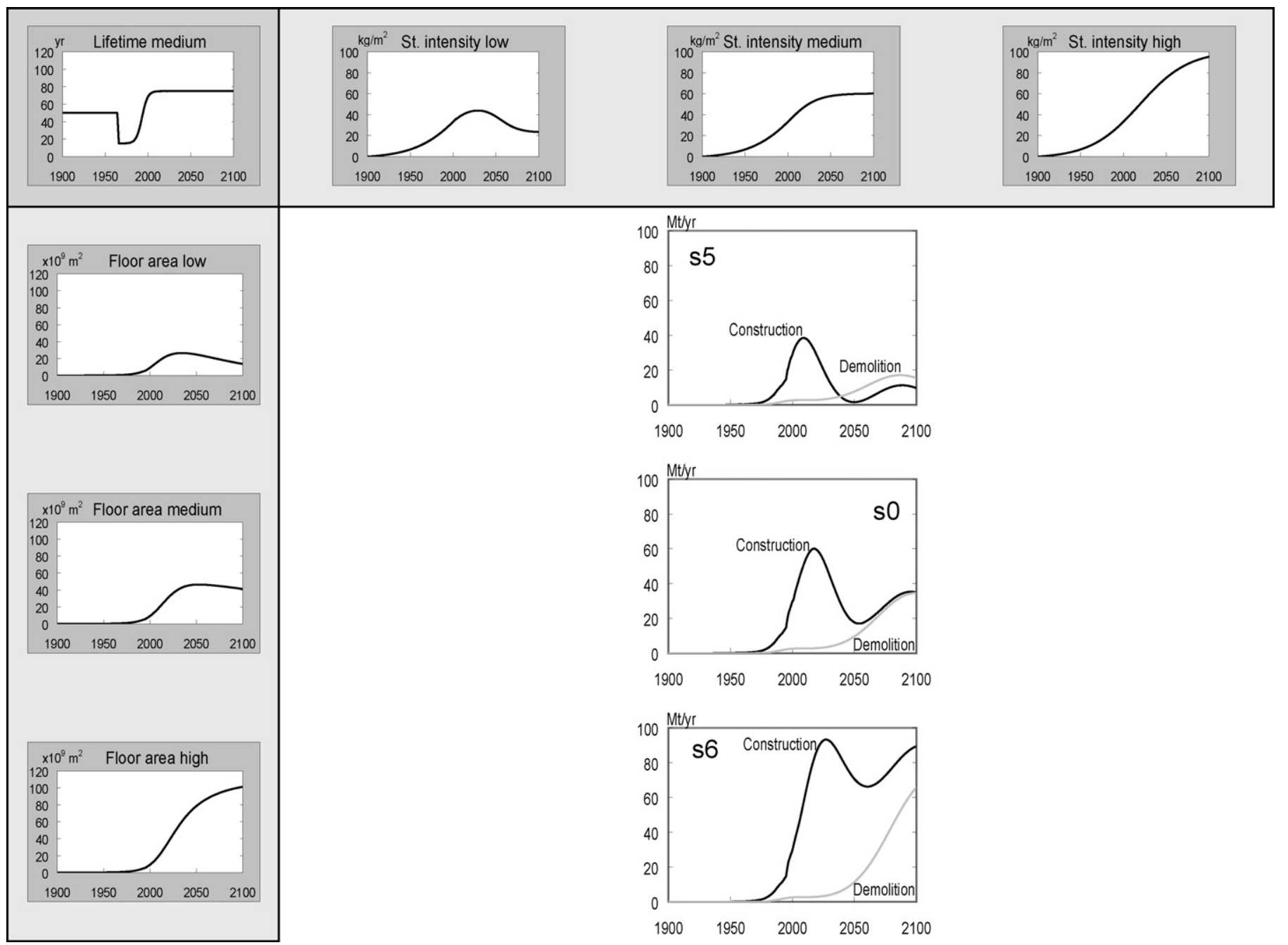

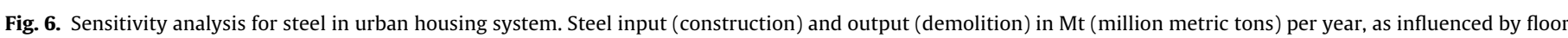

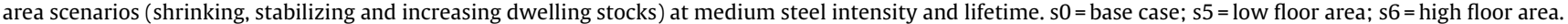


obsolete scrap from dwellings will eventually reach a level that is potentially sufficient to cover steel demand for residential construction entirely from secondary source and achieve a closed system (circular economy) for iron. In the low steel intensity scenario, substitute materials may lead to a lower demand for steel, so the supply of secondary steel will be even higher than the demand.

Compared to previous forecasts, this dynamic MFA study detects a dramatic change in trends of residential steel demand, which is likely to happen very soon. Forecasts of DRCSCC (2005) foresee a continuous increase of residential steel demand till 2010, while projection of Yang and Kohler (2008) expects a relatively stable input mass flow into China's buildings stock through 2050. The new finding of this study demonstrates the fail of trend expansion in forecasting material flows associated with long lifespan applications. It also illustrates the crucial role of life span and stock aging information in projections.

\subsection{Implications for steel industry}

\subsubsection{Oscillation indicated by the dynamic MFA in residential} steel demand implies the potentially serious overcapacity in China's steel production. The effect may exert to the global market when China will probably export its surplus steel at a more competitive price

The dynamic MFA in residential sector shows that oscillation occurs if the build-up time of the housing stock is shorter than the expected lifetime of the buildings. Considering the similar fast growth in Chinese non-residential buildings and infrastructures for the last two to three decades, we suspect that the oscillation would occur also in non-residential sector, and might be more severe in infrastructure construction due to the expected longer life span. If that would be the case, significant shrink in construction steel demand is expected in China for the decades to come.

China's rise to be world's largest steel producer is driven largely by its growing construction demand, which accounts for half of its annual steel output (Fig. 1). The probably decreasing construction demand implicates that China is likely to produce lots of surplus steel with its high production capacity. It means that Chinese construction steel producers may have to seek market in automobile or machinery sectors. However, this change will require a shift of production capacity from long products (normally used in construction) to flat products (normally used in automobile or machinery). Otherwise, Chinese steel industry will have to increase export at more competitive price, which will in turn lead to global overcapacity in the future.

\subsubsection{Lifetime of buildings and infrastructures is most influential} in steel demand projections. For the purpose of stabilizing steel demand, policies which may lead to higher replacement rate are more effective than those inducing higher steel intensity or bigger service size in residential buildings

Lifetime is the most influential factor. With very short lifetimes, the oscillation in construction steel demand can be almost not visible, while steel demand is much higher (Fig. 5). However, the lifetime parameter depends not only on the quality of houses and city infrastructures but also on cultural, economic, institutional and political factors, and so is still few understood. Therefore, better understanding on lifetimes of residential and non-residential buildings and infrastructures is essential for anticipating China's future construction steel demand.

Reducing service lifetime is the most effective measure on mitigating the oscillation, though it is ridiculous to shorten dwelling lifetime for stabilizing steel demand. However, policies, such as those which suggest replacing low efficient buildings according to certain energy standards may indeed result to shorter
Accumulated Net Steel Use 2001 - 2100

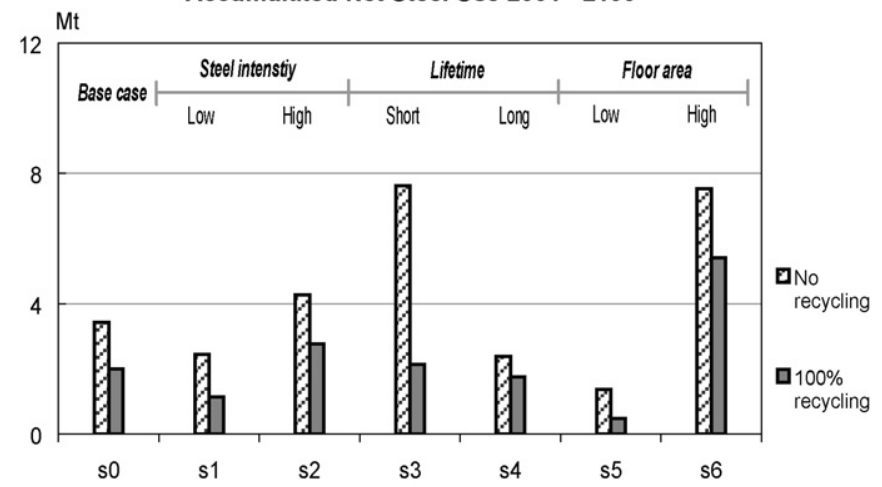

Fig. 7. Accumulated net residential steel use for no recycling (slope stripe) and 100\% recycling (solid) of scrap from 2001 to 2100 in Mt (million metric tons). s0=base case; s1 = low steel intensity; s2 = high steel intensity; s3 = short lifetime; s4 = long lifetime; s5 = low floor area; s6 = high floor area.

dwelling lifetime. As illustrated in Fig. 5, such policies will be more effective to create a stable steel demand than those promoting steel intensive structures or encouraging a more affluent dwelling size.

\subsubsection{Short lifetime anticipates the strong and early rise of scrap, implying the need to expand China's secondary steel production capacity}

While mitigating the oscillation in steel demand, short dwelling lifetime will also lead to strong and early rise of scrap (Fig. 5). The current Chinese steel production is mainly based on iron ore. ${ }^{2} \mathrm{~A}$ choice should be made to increase the scrap based steel production in China, so as to absorb the scrap locally, instead of mass scrap exporting combined with mass ore importing, for a more self-sufficient iron economy as well as a greener steel production in China. However, such a strategy would require an expansion of secondary steel production capacities and thereby further exacerbate the overcapacity problem.

\subsection{Environmental consequences}

The major environmental impacts of steel consumption for housing construction are on resource depletion and global climate change. The former can be assessed by the accumulated net steel use (Fig. 7), while the later can be assessed by the net $\mathrm{CO}_{2}$-equivalent emission (Fig. 8) for the investigated period (2001-2100). The calculation is made for two extreme recycling situations, representing no recycling or $100 \%$ recycling of the obsolete scrap from housing demolition, for urban residential buildings in base case scenario.

\subsubsection{Net steel use}

For no recycling situation, all the steel demanded for new housing construction has to be supplied from outside the urban housing system. The net steel use is assumed to be the same as the accumulated residential steel input during 2001-2100. For 100\% recycling situation, the scrap from housing demolition is assumed to be completely used to produce secondary steel to supply the steel demand for new housing construction. The net steel use is then assumed to be the gap between the accumulated scrap generation and the accumulated residential steel input for the period (2001-2100). The results are presented in Fig. 7.

\footnotetext{
2 See footnote 1.
} 
Accumulated $\mathrm{Net}_{\mathrm{CO}_{2}}$ Emission 2001 - 2100

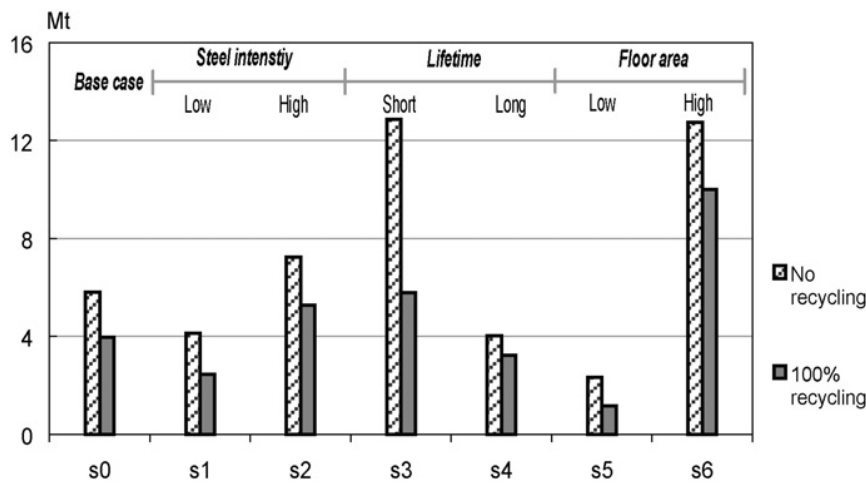

Fig. 8. Accumulated net $\mathrm{CO}_{2}$ emission of residential steel production for no recycling (slope stripe) and 100\% recycling (solid) of scrap from 2001 to 2100 in Mt (million metric tons). s0 = base case; $\mathrm{s} 1$ = low steel intensity; $\mathrm{s} 2$ = high steel intensity; s3 = short lifetime; s4 = long lifetime; s5 = low floor area; s6 = high floor area.

\subsubsection{Net $\mathrm{CO}_{2}$ emission}

All the steel input for new housing construction is assumed to be primary steel, produced by iron ore based process (Sintering/Coking/electric arc furnace (EAF)/Continuous casting/Rolling). While all the scrap released from housing demolition is assumed to be used to produce secondary steel by scrap based process (Sintering/Coking/blast furnace (BF)/basic oxygen furnace (BOF)/Continuous casting/Rolling). The $\mathrm{CO}_{2}$ emission factors for both processes are derived from those of Japanese iron and steel industry in 1999(MITI, 2000; Gielen and Moriguchi, 2002), adjusted with energy intensity of the best practice of Chinese steel enterprises in 2007 (MMI, 2008), with consideration of the high emission level due to China's coal based electricity generation. The resulted factors are, for iron ore based process $1690 \mathrm{~kg} \mathrm{CO} 2$ per ton primary steel production, and for scrap based process $399 \mathrm{~kg} \mathrm{CO}$ per ton secondary steel production. These factors are used here as the emission levels of Chinese steel production through 2100, though they may be both decreasing due to the continuous technical improvement. However, the significant savings of $\mathrm{CO}_{2}$ emission from replacing iron ore based production with scrap based production will be always the case.

The net $\mathrm{CO}_{2}$ emission in $100 \%$ recycling situation is calculated by subtracting the production emission of the primary steel demanded for new housing construction with the emission savings due to replacing the primary steel production with secondary steel production using all the scrap liberated from housing demolition. For no recycling situation, the net $\mathrm{CO}_{2}$ equals to the emission led by producing primary steel for new housing construction. The results are presented in Fig. 8.

The results show that, from environmental point of view, floor area stock is the most sensitive factor; high growth in residential floor area has the strongest impact on both resource depletion and global climate change, no matter recycling scrap or not.

Shortening lifetime is most effective to adjust the oscillation in residential steel demand. The environmental impacts of short lifetime strategies depend largely on the recycling scheme. The shorter the lifetime is, the better scrap recycling requires. For maximum recycling, shortening dwelling lifetime may cause no resource depletion and moderate rise of $\mathrm{CO}_{2}$ emissions. Because although a short lifetime demands big amount of steel to provide the same size of dwelling stock, it at the same time releases big amount of scrap, which provides the potential to circulate the steel within the residential sector instead claims from outside. Since steel production from scrap causes less $\mathrm{CO}_{2}$ emissions than from ore, in the case of proper recycling, the $\mathrm{CO}_{2}$ emissions in short lifetime scenario will increase much slower than its steel demand.

\section{Conclusions and outlook}

The model calculations indicate that a highly oscillating demand for steel is to be expected in China for the coming century. The longer life span of buildings or the lower floor area stock is, the stronger the oscillation will be. Opposite to most projections, this study shows a significant reduction in steel demand over the coming decades from China's residential sector, which currently accounts for $20 \%$ of the country's steel consumption. The use of a dynamic MFA model enables to include stock ageing, which is not present in other forecasts, and which seems to be a primary importance. The expected reduction in steel demand has obvious benefits both from an environmental point of view and from a resource conservation point of view. In the long run, the longer the life span is the lower the $\mathrm{CO}_{2}$ emissions related to construction activities, and the lower the use of potentially scarce resources. However, the expected oscillation has negative consequences as well for the stability of the steel producing industry, in China or even worldwide. The model calculations indicate that shortening the life span of the buildings is the most effective way to avoid the oscillation-but at obvious costs of higher $\mathrm{CO}_{2}$ emissions and resource use. These could be reduced to some extent by a strong emphasis on using secondary materials. Further research is indicated to explore the consequences of various options. To what extent can the demand for steel in construction be met by secondary materials, and what are limiting factors? What are trade-offs between recycling and durability? How can we stabilize markets with the least possible environmental and resource impacts? What can be the role of new construction materials or new building designs to replace steel? Such questions should be answered to indicate how China can progress on the road towards a sustainable construction sector.

\section{Acknowledgements}

This research was supported in part by Asia-link project "ProtEA" (EU No.CN/ASIA-LINK:110-744) and KNAW project "InnoMan" (Dutch Academy of Art and Science No. 09CDP009). The author Mingming Hu would like to thank Michiel Haas at Delft University of Technology for his helpful suggestions.

\section{Appendix A. Stock dynamics model for steel in housing stock}

The stock dynamics model for steel in China's rural and urban housing stock is formulated in following equations:

$$
\begin{aligned}
& A_{\mathrm{r}}(t)=P_{\mathrm{r}}(t) \cdot A_{\mathrm{rc}}(t)=P(t) \cdot(1-u(t)) \cdot A_{\mathrm{rc}}(t) \\
& A_{\mathrm{u}}(t)=P_{\mathrm{u}}(t) \cdot A_{\mathrm{uc}}(t)=P(t) \cdot u(t) \cdot A_{\mathrm{uc}}(t) \\
& \frac{\mathrm{d} A_{\mathrm{r}, \text { out }}(t)}{\mathrm{d} t}=\int_{t_{0}}^{t} L_{\mathrm{r}}\left(t, t^{\prime}\right) \cdot \frac{\mathrm{d} A_{\mathrm{r}, \text { in }}\left(t^{\prime}\right)}{\mathrm{d} t} \mathrm{~d} t^{\prime} \\
& \frac{\mathrm{d} A_{\mathrm{u}, \text { out }}(t)}{\mathrm{d} t}=\int_{t_{0}}^{t} L_{\mathrm{u}}\left(t, t^{\prime}\right) \cdot \frac{\mathrm{d} A_{\mathrm{u}, \text { in }}\left(t^{\prime}\right)}{\mathrm{d} t} \mathrm{~d} t^{\prime} \\
& L_{\mathrm{r}}\left(t, t^{\prime}\right)=\frac{1}{\sigma_{\mathrm{r}} \sqrt{2 \pi}} \cdot e^{-\left(t-t^{\prime}-\tau_{\mathrm{r}}\right)^{2} / 2 \sigma_{\mathrm{r}}{ }^{2}} \\
& L_{\mathrm{u}}\left(t, t^{\prime}\right)=\frac{1}{\sigma_{\mathrm{u}} \sqrt{2 \pi}} \cdot e^{-\left(t-t^{\prime}-\tau_{\mathrm{u}}\right)^{2} / 2 \sigma_{\mathrm{u}}^{2}} \\
& \frac{\mathrm{d} A_{\mathrm{r}, \text { in }}(t)}{\mathrm{d} t}=\frac{\mathrm{d} A_{\mathrm{r}}(t)}{\mathrm{d} t}+\frac{\mathrm{d} A_{\mathrm{r}, \text { out }}(t)}{\mathrm{d} t} \\
& \frac{\mathrm{d} A_{\mathrm{u}, \text { in }}(t)}{\mathrm{d} t}=\frac{\mathrm{d} A_{\mathrm{u}}(t)}{\mathrm{d} t}+\frac{\mathrm{d} A_{\mathrm{u}, \text { out }}(t)}{\mathrm{d} t}
\end{aligned}
$$


$\frac{\mathrm{d} M_{\mathrm{r}, \text { in }}(t)}{\mathrm{d} t}=\frac{\mathrm{d} A_{\mathrm{r}, \text { in }}(t)}{\mathrm{d} t} \cdot M_{\mathrm{ra}}(t)$

$\frac{\mathrm{d} M_{\mathrm{u}, \text { in }}(t)}{\mathrm{d} t}=\frac{\mathrm{d} A_{\mathrm{u}, \text { in }}(t)}{\mathrm{d} t} \cdot M_{\mathrm{ua}}(t)$

$\frac{\mathrm{d} M_{\mathrm{r}, \text { out }}(t)}{\mathrm{d} t}=\int_{t_{0}}^{t} L_{\mathrm{r}}\left(t, t^{\prime}\right) \cdot \frac{\mathrm{d} M_{\mathrm{r}, \text { in }}\left(t^{\prime}\right)}{\mathrm{d} t} \mathrm{~d} t^{\prime}$

$\frac{\mathrm{d} M_{\mathrm{u}, \text { out }}(t)}{\mathrm{d} t}=\int_{t_{0}}^{t} L_{\mathrm{u}}\left(t, t^{\prime}\right) \cdot \frac{\mathrm{d} M_{\mathrm{u}, \text { in }}\left(t^{\prime}\right)}{\mathrm{d} t} \mathrm{~d} t^{\prime}$

$\frac{\mathrm{d} M_{\mathrm{r}}(t)}{\mathrm{d} t}=\frac{\mathrm{d} M_{\mathrm{r}, \text { in }}(t)}{\mathrm{d} t}-\frac{\mathrm{d} M_{\mathrm{r}, \text { out }}(t)}{\mathrm{d} t}$

$\frac{\mathrm{d} M_{\mathrm{u}}(t)}{\mathrm{d} t}=\frac{\mathrm{d} M_{\mathrm{u}, \text { in }}(t)}{\mathrm{d} t}-\frac{\mathrm{d} M_{\mathrm{u}, \text { out }}(t)}{\mathrm{d} t}$

1) National total population $(P)$

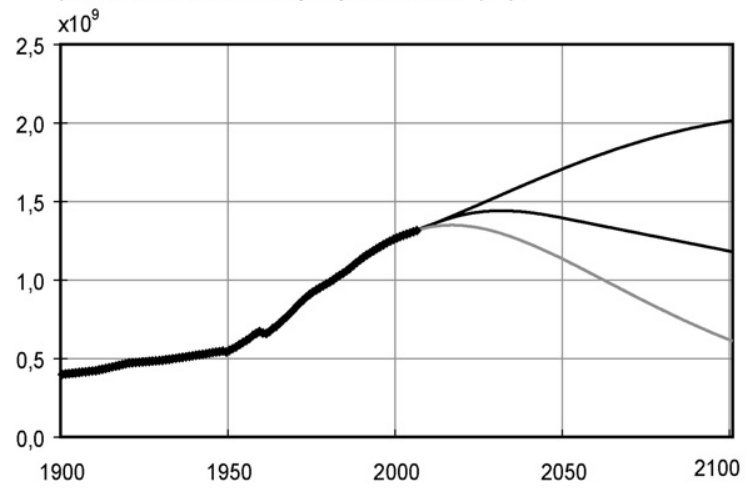

3) Per capita floor area in rural housing $\left(A_{r c}\right)$

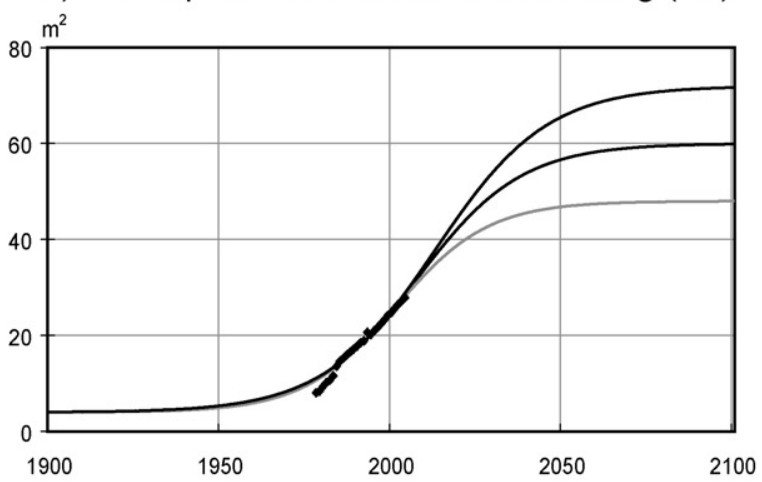

5) Average rural housing lifetime $\left(L_{r}\right)$

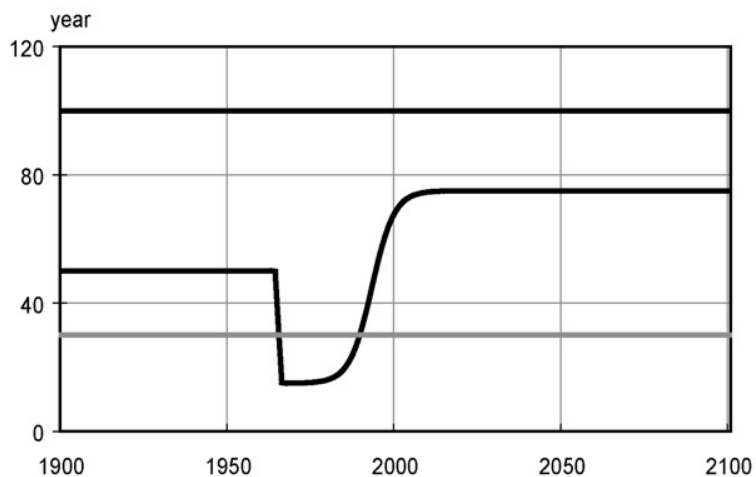

Eqs. (1) and (2) indicate the urban and rural housing stocks are determined by the size of national population, the level of urbanization and per capita housing demand in either region. Eqs. (3) and $\left(3^{\prime}\right)$ illustrate the outflow from the housing stock is determined by the past inflow, with a delay of the service life of the houses. Eqs. (4) and $\left(4^{\prime}\right)$ assume the lifetime of rural and urban houses follows normal distribution function. Eqs. (5) and (5') forecast the future rural and urban inflows of housing stock by balance the rural and urban housing processes, respectively. Eqs. (6) and (6') forecast link the service system of rural and urban housing floor area to the related material system with the material density parameters $M_{\mathrm{ra}}(t)$ and $M_{\text {ua }}(t)$. Corresponding to Eqs. (3) and (3'), Eqs. (7) and ( $\left.7^{\prime}\right)$ represent that the rural and urban material outflows are determined by previous inflows after delaying a lifetime $L_{\mathrm{r}}\left(t, t^{\prime}\right)$ or $L_{\mathrm{u}}\left(t, t^{\prime}\right)$. Eqs. (8) and $\left(8^{\prime}\right)$ represent that the material stocks in the rural and urban housing systems can be calculated according to the material inflows and outflows.

\section{2) Urbanization rate (u)}

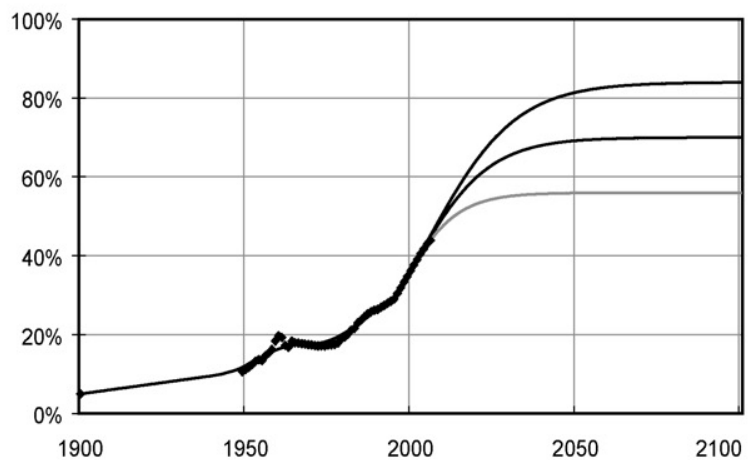

4) Per capita floor area in urban houisng $\left(A_{u c}\right)$

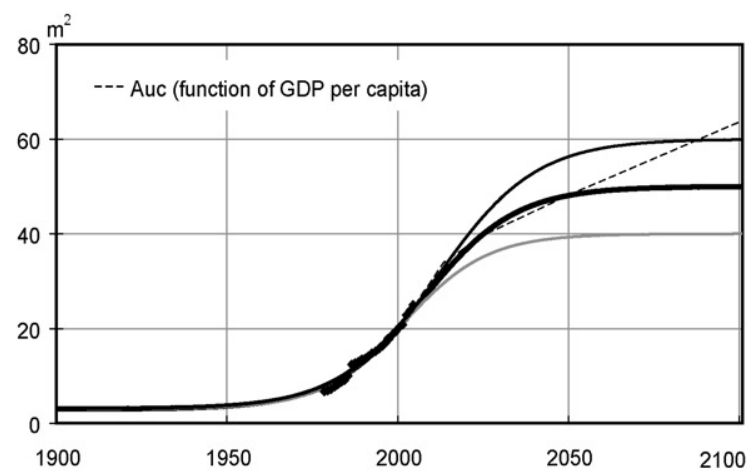

6) Average urban housing lifetime (Lu)

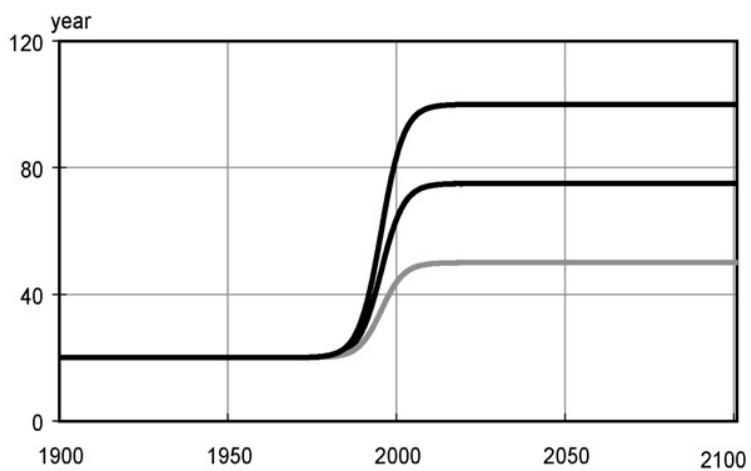

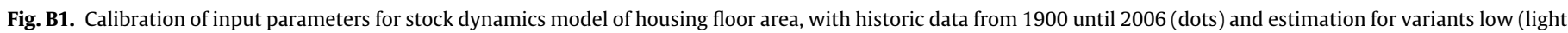
grey), medium (dark grey) and high (black) from 2007 until 2100. Source: Hu et al. (2009). 


\section{Appendix B. Quoted calibration}

See Fig. B1.

Calibration of the six external parameters $\left(P, u, A_{\mathrm{rc}}, A_{\mathrm{uc}}, L_{\mathrm{r}}\right.$, and $L_{\mathrm{u}}$ ) are quoted from the floor area stock dynamics model for China's rural and urban housing systems (Hu et al., 2009). For each external parameter, a low, medium and high variant are estimated for the future period. In the early study of Hu et al. (2009), the parameter of urban per capita floor area was estimated as a function of China's per capita GDP as a fourth variant for the purpose of comparison. This scenario is omitted in this study for housing related steel flows, because the path of future residential stock development resulted by the GDP driving urban per capita floor area is already covered by the variance between the lowest urban stock demand resulted by the low urban population and low per capita floor area scenario, and the highest stock demand resulted by high urban population and high per capita floor area scenario.

\section{References}

Beijing Municipal Chorography Compiling Council (BMCCC). Beijing chorography Volume: Architecture chorography, 1999, Beijing, China (in Chinese).

Bergsdal H, Brattebø H, Bohne RA, Müller DB. Dynamic material flow analysis for Norway's dwelling stock. Building Research \& Information 2007;35(5):55770.

China Iron and Steel Association (CISA). China steel yearbook; 2008, Beijing, China (in Chinese).

Development Research Center of the State Council of China (DRCSCC). Forecast report of the steel consumption of China 2005-2010; 2005, Beijing, China (in Chinese).

Gielen D, Moriguchi Y. $\mathrm{CO}_{2}$ in the iron and steel industry: an analysis of Japanese emission reduction potentials. Energy Policy 2002;30:849-63.

Hu M, Bergsdal H, Müller DB. Dynamics of the urban and rural housing stocks in China. Building Research \& Information 2009 (under review).
Liu T, Hu D. Environmental impact of residential building construction in Beijing. Journal of Graduate School of the Chinese Academy of Sciences 2006;23(2):231-41.

Lu ZW. Iron-flow analysis for the life cycle of steel products: a study on the source index for iron emission. Acta Metallurgica Sinica 2002;38(1):58-68 (in Chinese).

Müller DB. Long-term coordination of timber production and consumption using a dynamic material and energy flow analysis. Journal of Industrial Ecology 2004;8(3).

Müller DB. Stock dynamics for forecasting material flows-case study for housing in the Netherlands. Ecological Economics 2006;59:142-56.

Ministry of International Trade and Industry (MITI). Yearbook of iron and steel statistics 1999. Tokyo: Research and Statistics Department Minister's Secretariat; 2000.

Ministry of Metallurgical Industry (MMI). Yearbook of iron and steel industry of China; 2008, Beijing.

National Bureau of Statistics of China (NBSC). Statistical compendium of China 1949-2004. Beijing: China Statistical Press; 2005.

National Bureau of Statistics of China (NBSC). China statistical yearbook 1980-2007. Beijing: China Statistical Press; 2007.

Price L, Sinton J, Worrell E, Phylipsen D, Xiulian H, Ji L. Energy use and carbon dioxide emissions from steel production in China. Energy 2002;27:429-46.

United Nations Population Division (UNPD). World population in 2300, Draft of 9 December, New York: United Nations; 2003.

United Nations Population Division (UNPD). World population prospects: the 2006 revision. United Nations, New York; 2006, http://esa.un.org/unpp [accessed 07.09].

United Nations Population Division (UNPD). World urbanization prospects: the 2007 revision. New York: United Nations; 2007, http://esa.un.org/unup [accessed 07.09].

Wang T, Müller DB, Graedel TE. Forging the anthropogenic iron. Environmental Science and Technology 2007;41:5120-9.

Wang T, Mao J, Johnson J, Reck BK, Graedel TE. Anthropogenic metal cycles in China. Journal of Material Cycles and Waste Management 2008;10:188-97.

Wang Z. Mitigate resource supply tenseness by sensibly using scrap. Nonferrous Metal Recycling and Use 2004;3:25-7 (in Chinese).

World Steel Association (WSA). Steel statistical yearbook. Brussels, Belgium: WSA 2008.

World Steel Association (WSA). Latest steel statistics. 2009, http://www.worldsteel org/?action=lateststeellist [accessed 07.09].

Yang W, Kohler N. Simulation of the evolution of the Chinese building and infrastructure stock. Building Research \& Information 2008;36(1):1-19. 